\title{
27. REGIONAL SITE SURVEYS, SITES 259, 262, 263
}

\section{J. J. Veevers, Macquarie University, Sydney, N.S.W., Australia}

Immediately before drilling Sites 259 and 262, and after drilling Site 263, we received from the Australian Bureau of Mineral Resources (BMR) copies of seismic profiles made currently near these sites. These profiles are valuable in elucidating the regional structure of the sites, and we are grateful to the Bureau for releasing this information. A tentative interpretation of the seismic profiles is shown in the accompanying line drawings.

\section{SITE 259}

The BMR track passes within 5 nautical miles $(9.3$ $\mathrm{km}$ ) of Site 259 (Figure 1) and provides details of the rugged local physiography on the landward side of the site (see fig. 2 of Site 259 report). Regionally, the BMR profiles (Figure 2) show the sharp separation between continental and oceanic structure along the WallabyPerth scarp or lower slope, above which is a narrow incised marginal plateau at a general level of 3000 meters. The profiles show furthermore that Site 259 lies only 12 miles $(19.3 \mathrm{~km})$ from the foot of the WallabyPerth scarp.

\section{SITE 262}

The profiles located near Site 262 (Figure 3) are shown in Figure 4 . They reveal a uniform acoustic stratigraphy near the site beneath the trough axis and at the foot of the Australian flank. The chief identified reflector is $R_{1}$ of Veevers et al. (in preparation), whose distinctive character is shown (fig. 13, Chapter 7). As in other profiles in this region, the connection of $R_{1}$ between the trough axis and the Sahul Shelf is obscured by faults (suspected but not plotted in the BMR profile). A characteristic anticlinal ridge at the foot of the Timor flank (anticline 1 of Veevers et al., in preparation) in this region is clearly shown in all three profiles.

\section{SITE 263 (FIGURES 5 AND 6)}

East-west profiles (CD, FE, GH) show the Cuvier Abyssal Plain and a uniform continental margin of a smooth upper slope, a deeply incised lower slope, and a narrow continental rise. As seen in the Glomar Challenger records, the Cuvier Abyssal Plain has a basement reflector, presumably oceanic basalt, draped by a thick transparent layer, in turn overlain by horizontal wellstratified sediments. The distinct character of the basement reflector can be traced landward beneath the lower slope in $\mathrm{CD}$ and $\mathrm{FE}$, and, as shown most clearly in CD, is continuous with an angular unconformity beneath the upper slope. This unconformity is probably the same surface as Reflector 4 of Veevers et al. (in press) beneath the Exmouth Plateau and was probably shaped during the rupture of the continental margin in the Early Cretaceous, and is therefore the same age as the adjacent oceanic basalt basement. Consequently, the transparent sediment layer above the oceanic basalt is equivalent to the Cretaceous sediments landward. At Pendock No. 1 Well (Geary, 1970), whose projected position is shown in profile FE (Figure 6), the unconformity separates early Carboniferous and older sediments below from Aptian and younger sediments above, and the similarity between the Aptian to Cenomanian shale sequence in Pendock No. 1 and the Cretaceous clay of Site 263 is striking.

\section{REFERENCES}

Geary, J. K., 1970. Offshore exploration of the Southern Carnarvon Basin: Australian Petrol. Expl. Assoc. J., v. 10, p. 915.

Veevers, J. J., Falvey, D. A., Hawkins, L. V., and Ludwig, W. $\mathrm{J}$, in press. Seismic reflection measurements of the northwest Australian margin and adjacent deeps: Am. Assoc. Petrol. Geol. Bull.

Veevers, J. J., Windisch, C. C., and Falvey, D. A., in preparation. Timor Trough - a modern fore deep. 


\section{J. J. VEEVERS}

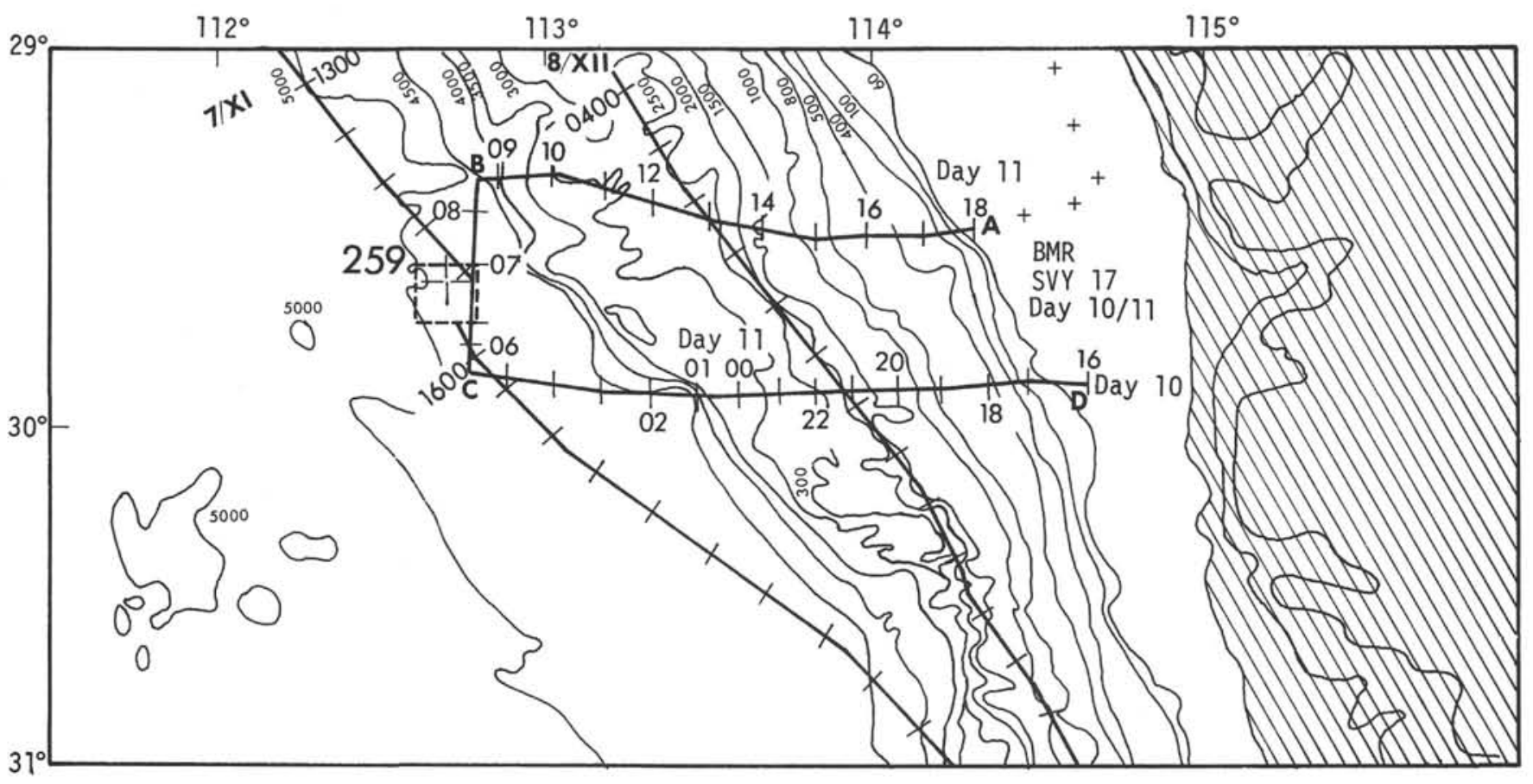

Figure 1. Track of BMR SVY-17 in vicinity of Site 259.

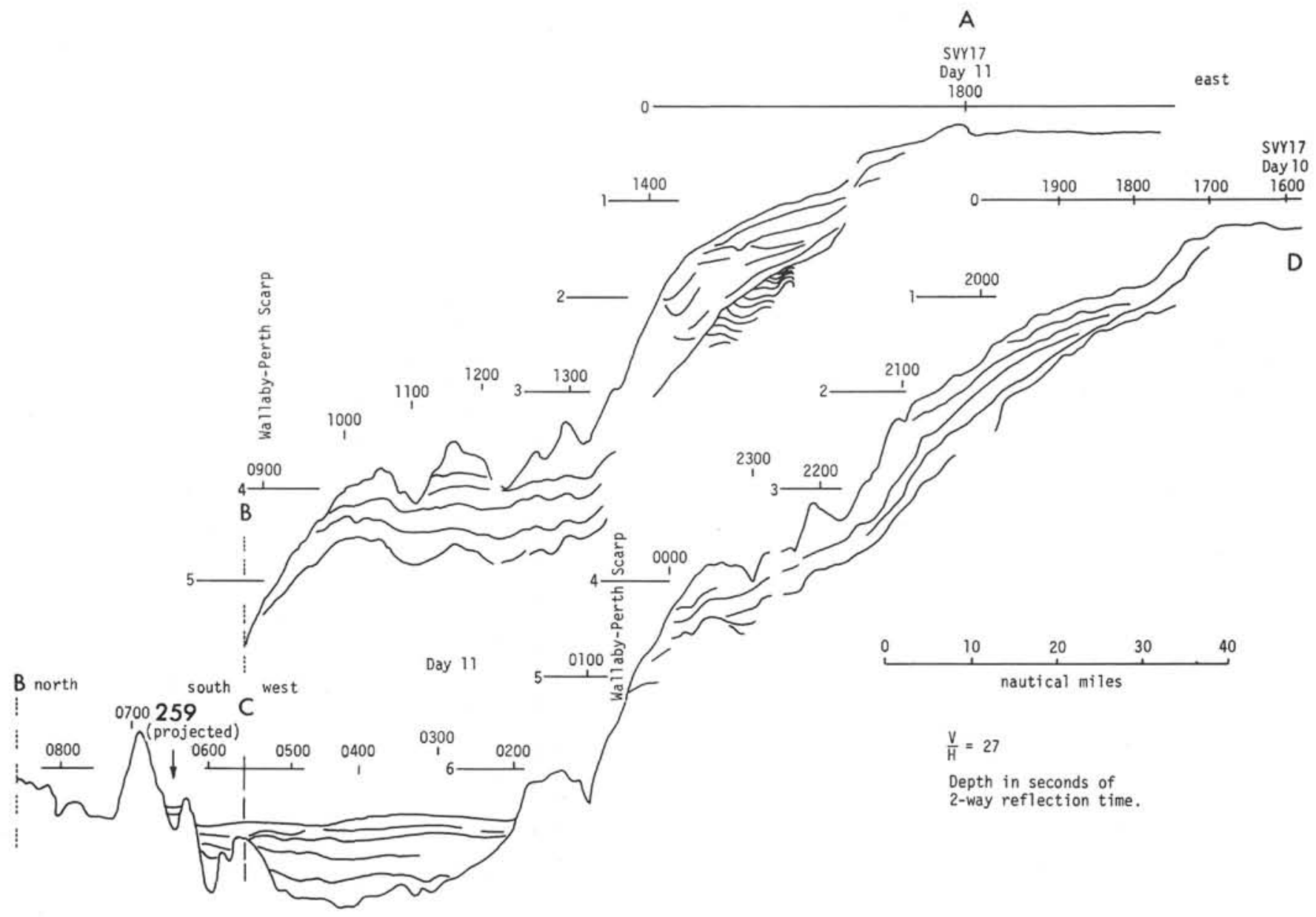

Figure 2. Seismic profiles of BMR SVY-17 in vicinity of Site 259. 


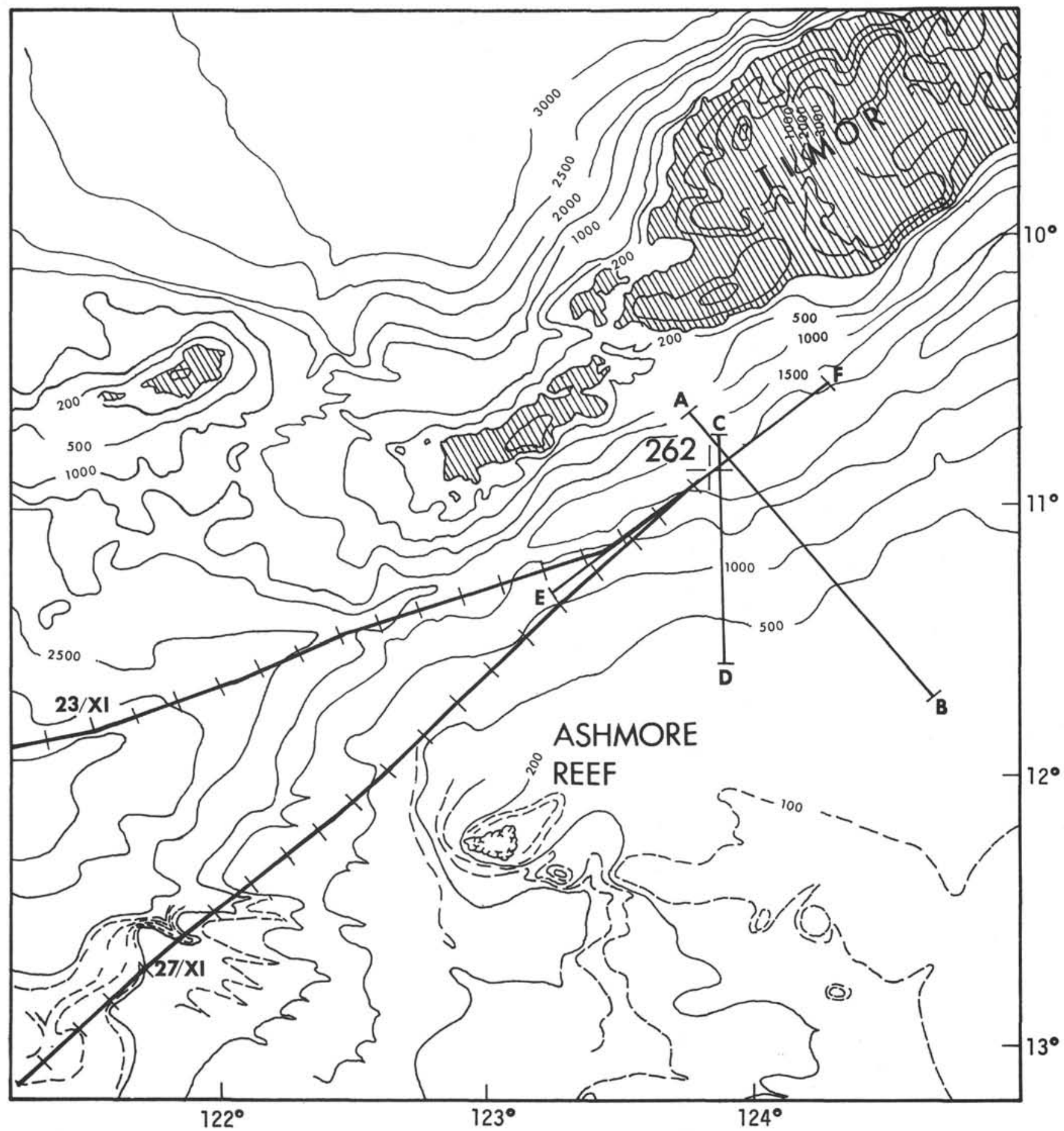

Figure 3. Location of seismic profiles in vicinity of Site 262. 


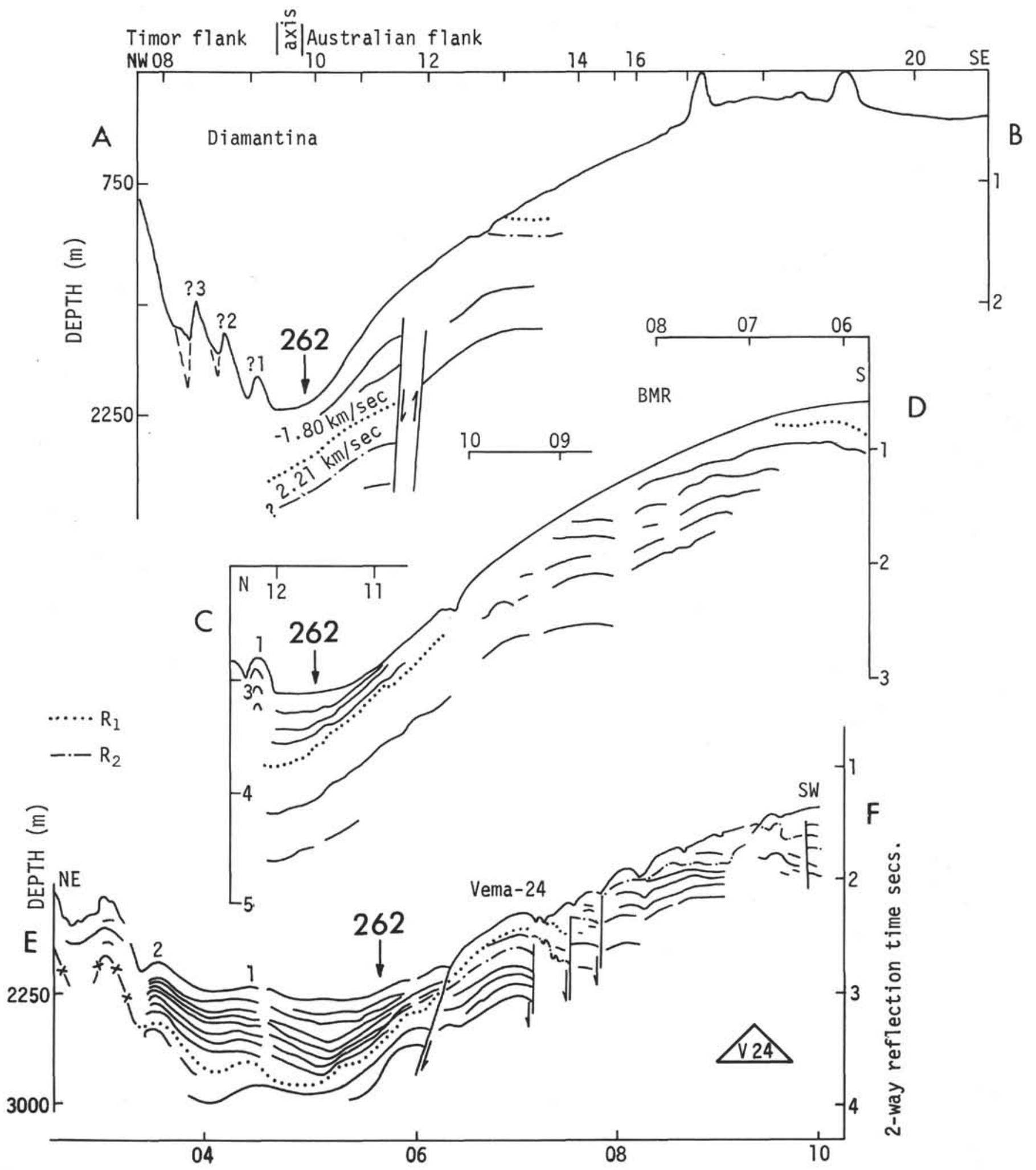

Figure 4. Seismic profiles in vicinity of Site 262. 


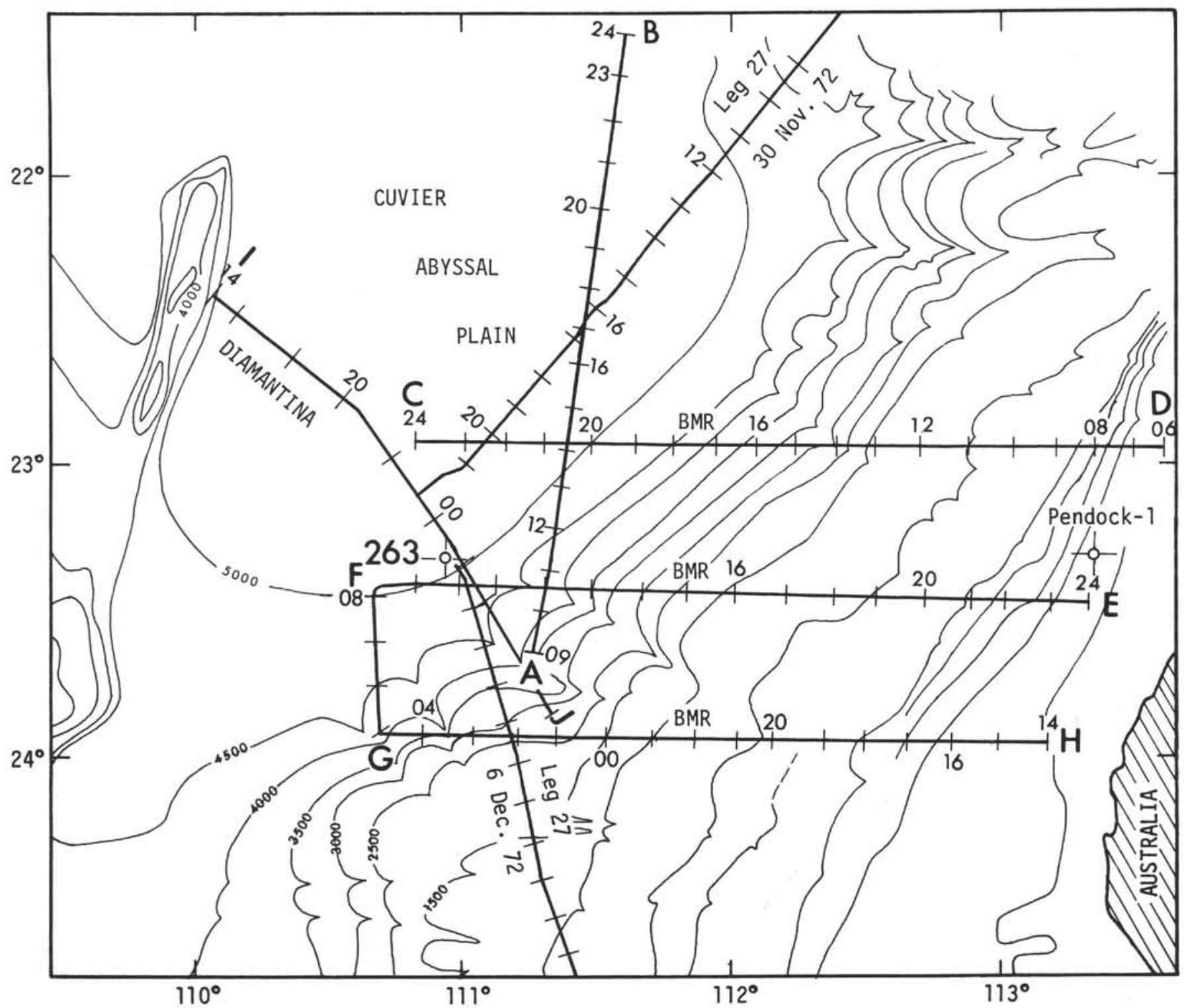

Figure 5. Location of seismic profiles in vicinity of Site 263. 


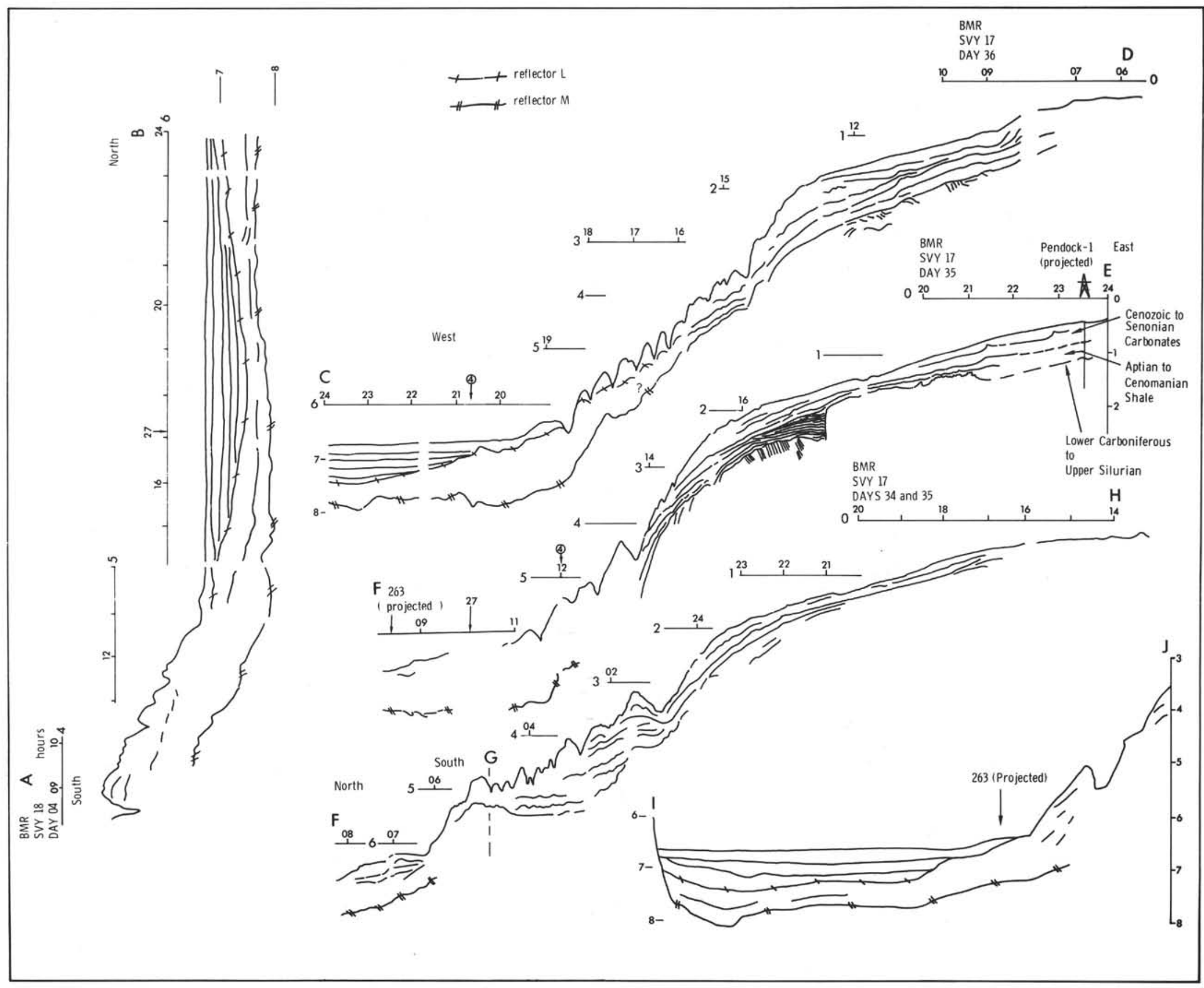

Figure 6. Seismic profiles in vicinity of Site 263. 